\title{
BDDManager: Uma ferramenta de gerenciamento de testes comportamentais
}

\section{Vinícius A. Pereira*, Plinio R. S. Vilela}

\section{Resumo}

Teoricamente, a habilidade de programar não é requisito para escrever testes automatizados, porém geralmente esta habilidade se faz necessária devido à conexão intrínseca entre os cenários de teste e sua implementação em código. $\mathrm{Na}$ maior parte dos casos, os programadores que fizeram o código acabam escrevendo os cenários de teste. Esta sitituação permite o surgimento de testes tendenciosos, uma vez que o programador quer provar que seu código funciona. Com base neste cenário, nós apresentamos o BDDManager: uma ferramenta que premite que nãoprogramadores gerenciem testes comportamentais automatizados.

\section{Palavras-chave:}

Behavior Driven Development, Teste de Software, User Story.

\section{Introdução}

Baseado na prática do Extreme Programming chamada test-first, o Test Driven Development (TDD) é um processo iterativo que consiste em escrever os testes antes de escrever o código. Desta forma, os testes falham até que o código real seja escrito, e fazer com que os testes passem serve como indicador de progresso. Criado a partir do TDD, Behavior Driven Development (BDD) é uma metodologia ágil que utiliza user stories para descrever o comportamento esperado do sistema a partir do ponto de vista de um usuário final. Tais user stories são escritas em linguagem natural, de forma que podem ser compreendidas por todos os membros do projeto'.

Tipicamente, uma user story contém três partes: (i) o nome da funcionalidade, (ii) a caracterização do usuário contendo sua descrição, seu desejo em relação à funcionalidade e a justificativa do desejo, e (iii) um conjunto de cenários que descrevem o comportamento esperado da funcionalidade.

Cada cenário representa um caso de teste e é composto por um conjunto de steps baseados nas palavras chaves given, when e then. Os steps iniciados com given descrevem um conjunto de pré-condições, enquanto os que começam com when descrevem um conjunto de eventos e os iniciados com then descrevem o resultado esperado após a ocorrência dos eventos.

Uma vez escrita a user story, é necessário considerável esforço e colaboração entre a equipe de teste e de desenvolvimento para transformá-la em um teste que possa ser de fato executado.

Neste trabalho, nós conceituamos e desenvolvemos uma ferramenta que visa automatizar esta etapa, permitindo que qualquer pessoa, desde que entenda do domínio de negócio do software, gerencie testes comportamentais automatizados, deixando a equipe de programação responsável somente por implementar os steps para fazer o teste passar.

\section{Resultados e Discussão}

Com base no problema apresentado e em artefatos disponibilizados pela empresa Rail Movement Planner (Railmp), foi criado o BDDManager, cuja interface está representada na figura 1. Nela, podemos ver que as stories são apresentadas do lado esquerdo, os steps do lado direito e no centro o usuário pode editar, consultar ou escrever novas stories e, caso novos steps sejam criados, estes são indicados ao usuário e uma pendência é gerada automaticamente no código fonte dos testes para que sejam implementados pelos programadores.

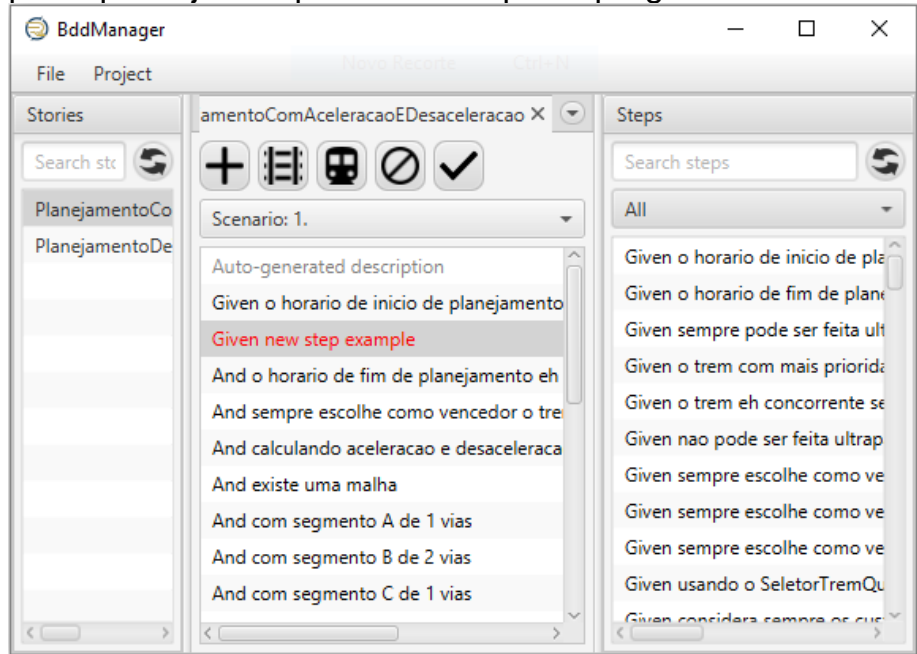

Figura 1. Interface da ferramenta.

Durante este trabalho, também foi elaborado e submetido um artigo científico para a Sessão de Ferramentas do Congresso Brasileiro de Software (CBSoft).

\section{Conclusões}

Devido aos artefatos disponibilizados, a ferramenta foi criada visando dar suporte a testes relacionados a roteamento de trens. Contudo, acreditamos que a solução encontrada pode ser aplicada a diferentes áreas de negócio e propomos como trabalho futuro a criação de uma versão mais genérica da ferramenta, que possa ser aplicada em outros ambientes.

\section{Agradecimentos}

Agradeço ao Prof. Plinio Vilela que, em parceria com a Railmp, acreditaram que eu teria capacidade para desenvolver 0 trabalho inicialmente proposto, disponibilizando seus artefatos e espaço para que a pesquisa pudesse ser realizada. Agradeço novamente a Railmp por ter fomentado a pesquisa.

${ }^{1}$ Soeken, M., Wille, R., and Drechsler, R. (2012). Assisted behavior driven developmentusing natural language processing. In Furia, C. A. and Nanz, S., editors,Objects,Models, Components, Patterns, pages 269-287, Berlin, Heidelberg. Springer BerlinHeidelberg. 